\title{
Prevalence of coronary artery disease risk factors in patients undergoing coronary artery bypass surgery in West Azerbaijan province
}

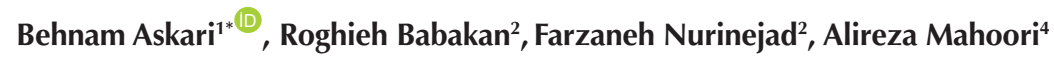 \\ ${ }^{1}$ Department of Cardiovascular Surgery, Seyed-al-Shohada Heart Center, Urmia University of Medical Sciences, Urmia, Iran \\ ${ }^{2}$ General Physician, Urmia University of Medical Sciences, Urmia, Iran \\ ${ }^{3}$ Department of Anesthesiology, Seyed-al-Shohada Heart Center, Urmia University of Medical Sciences, Urmia, Iran
}

*Corresponding Author: Behnam Askari, Address: Seyed-al-Shohada Heart Center, 17 Shahrivar Street, Urmia, Iran, Tel: 098 4432375908, Email: askaribehnam@ymail.com

\begin{abstract}
Background and aims: Coronary artery disease (CAD) is one of the main causes of death worldwide and coronary artery bypass grafting (CABG) surgery accounts for $1.4 \%$ of all operating room procedures. Considering the importance of the above-mentioned issue, the present study aimed to assess CAD risk factors in CABG patients to provide more accurate information for health authorities.

Methods: To this end, data of all patients with isolated primary on-pump CABG were collected from March 2014 to March 2016. The major risk factors of CAD were recorded as a history of cigarette smoking, dyslipidemia, hypertension, diabetes mellitus (DM), advanced age, a family history of CAD, obesity, and male gender. Statistical analyses were performed by SPSS using a $t$ test, as well as the chi-square and Fisher exact tests, and the $P$ value less than 0.05 was considered statistically significant.

Results: During a 24-month period, 895 patients underwent isolated primary on-pump CABG in the only open-heart surgery center in the West Azerbaijan province of Iran. The mean age of the patients was $60.4 \pm 10.3$ years (within the range of 40 to 93 years). In addition, most of the patients amounting to 525 cases $(58.7 \%)$ were in the age group of $55-70$ years and had two or more risk factors. Further, $98.8 \%$ of males (age $\geq 45$ ) and $68.2 \%$ of females (age $\geq 55$ ) were old, and $73.3 \%$ and $26.7 \%$ of the patients were men and women, respectively. Furthermore, risk factors such as hypertension, cigarette-smoking, DM, hyperlipidemia, obesity, and family history were observed in $53.3 \%, 47.9 \%, 37.8 \%, 28.5 \%, 61.1 \%$, and $19.3 \%$ of the patients, respectively. As regards gender, the prevalence of coronary risk factors like hypertension ( 60.7 vs. $50.6 \%, P=0.005)$, DM (51.9 vs. $32.6 \%, P=0.001$ ), hypercholesterolemia ( 43.5 vs. $23 \%, P=0.001$ ), and obesity ( 68.2 vs. $58.5 \%, P=0.005)$ were higher in women but other factors such as smoking (19.2 vs. $58.4 \%, P=0.001)$ and positive family history (14.6 vs. $21 \%, P=0.01$ ) were higher in men.

Conclusion: Overall, the prevalence of most risk factors was more common among under 55-year group, especially in women, and this is a warning for increasing CADs in the future.

Keywords: Coronary artery disease, Coronary artery bypass graft, Risk factors
\end{abstract}

Received: 12 May 2018, Accepted: 9 June 2018, ePublished: 30 August 2019

\section{Introduction}

Coronary artery disease $(\mathrm{CAD})$ is considered as the most common form of cardiovascular disease with an estimated prevalence of $6.9 \%$ and $6 \%$ in men and women, respectively (1). In addition, CAD is one of the most prevalent causes of death around the world and is responsible for 1 in 5 deaths in the United States (2). CAD has also been reported as the most common cause of death in Iran during the past 10 years (3).

Each year, more than 300000 patients undergo coronary artery bypass grafting (CABG) surgery in the United States. Although the introduction of percutaneous coronary intervention has decreased the use of CABG in the past decade, CABG remains the most common cardiac surgery (4). In-hospital mortality rate after CABG surgery is about $1 \%$ for the lowest risk elective patients and $2 \%-5 \%$ for all patients (5). Further, the average cost of hospitalization and physician fees for a coronary bypass operation is different in various countries, for example, ranging from $\$ 1600$ in India to $\$ 75000$ in the United States (6). In the global INTERHEART study of patients from 52 countries, nine potentially modifiable factors accounted for over $90 \%$ of the population-attributable risk of a first myocardial infarction, including smoking, dyslipidemia, hypertension, diabetes, abdominal obesity, psychosocial factors, the lack of the daily consumption of fruits and vegetables, regular alcohol consumption, and the lack of regular physical activity (7). Although CAD is the most serious disease in developing countries, developed countries have significantly reduced the mortality rate of this disease by preventive actions during recent decades (8).

The prevalence of CAD, coronary risk factors, and the

(C) 2019 The Author(s); Published by Shahrekord University of Medical Sciences. This is an open-access article distributed under the terms of the Creative Commons Attribution License (http://creativecommons.org/licenses/by/4.0), which permits unrestricted use, distribution, and reproduction in any medium, provided the original work is properly cited. 
metabolic syndrome is more common in Iran compared to western countries and similar to our regional countries in the Middle East (9).

Many patients undergoing CABG surgery have cardiovascular risk factors which are preventable (10). According to large-scale studies, the modification of CAD risk factors is important in preventing the progression of atherosclerosis following CABG while improving survival in these patients (11).

Considering the above-mentioned discussion, the current study sought to evaluate CAD risk factors in CABG patients in Seyed-al-Shohada Cardiovascular Center of Urmia during 2014-2016. By determining such risk factors, it is possible to provide more accurate data for health authorities to perform preventive actions in this regard.

\section{Materials and Methods}

This study was retrospectively conducted on patients undergoing CAGB surgery in Seyed-al-shohada Cardiovascular Center in Urmia. This heart center is the only open heart surgery center in West Azerbaijan province with about three million patients. The data of all patients with isolated primary on-pump CABG were collected during March 2014-2016. The major recorded risk factors of CAD included a history of cigarettesmoking, dyslipidemia, hypertension, diabetes mellitus (DM), advanced age, a family history of CAD, obesity, and male gender.

Hypertension was defined as systolic blood pressure $>140 \mathrm{~mm} \mathrm{Hg}$, diastolic blood pressure > $90 \mathrm{~mm} \mathrm{Hg}$, or selfreported use of antihypertensive medications. Similarly, DM was defined as a fasting blood glucose level of $>126$ $\mathrm{mg} / \mathrm{dL}$, 2-hour post-prandial blood glucose level > $200 \mathrm{mg} /$ $\mathrm{dL}$, or pharmacological treatment for DM. Dyslipidemia was also referred to as low-density lipoprotein level $>100$ $\mathrm{mg} / \mathrm{dL}$ or high-density lipoprotein $<40 \mathrm{mg} / \mathrm{dL}$ in men and $<50 \mathrm{mg} / \mathrm{dL}$ in women, or triglyceride $>150 \mathrm{mg} / \mathrm{dL}$ or currently receiving anti-lipid treatment. A family history of premature CAD was coded as positive if a first-degree relative had a coronary event before the age of 55 years in males and before the age of 65 years in females. Likewise, smoking was defined as the number of smoked cigarettes anytime during the year prior to the surgery.

The only exclusion criterion in our study was incomplete medical records. Statistical analyses were performed using SPSS, version 20, and statistical significance was assessed at the level of 0.05 . Eventually, quantitative values were compared using the t-test for independent groups, and the Chi-square and Fisher's exact tests were applied for categorical data.

\section{Results}

During a 24-month period (March 2014 to March 2016), 895 patients underwent CABG. The prevalence of coronary risk factors of all patients is shown in Table 1 . There were 656 men (73.3\%) and 239 women (26.7\%). Furthermore, the mean age was $60.40 \pm 10.03$ years (from 40 to 93 years), and the mean age of men and women was $60.02 \pm 10.30$ and $61.43 \pm 9.18$ years, respectively $(P=0.06)$. A total of 231 patients (25.8\%) were under 55 years old, the majority of the patients $(n=525,58.7 \%)$ were within the age range of 55-70 years, and 139 patients (15.5\%) were older than 70 years. Moreover, most of the patients had two or more risk factors $(95.8 \%)$. Figure 1 illustrates the number of risk factors.

The distribution of major risk factors based on the gender and the age of the patients is summarized in Tables 2 and 3. In most studies, there is no definite limit for the old age. According to the National Heart, Lung, and Blood Institute of the United States, the risk of CAD increases for women and men at the ages of 55 and 45, respectively. On the other hand, scoring for mortality prediction was performed from the age of 60 in the EuroSCORE system. Therefore, we used both NHLB institute and EuroSCORE ranking.

\section{Discussion}

An exact estimate of the prevalence of CAD risk factors remains elusive, but the prevalence of important risk factors has changed over time with increased awareness and changes in diet and lifestyle (2). Many individuals in the general population have one or more risk factors of $\mathrm{CAD}$, and over $90 \%$ of CAD events occur in persons with at least one risk factor. On the other hand, the absence of major risk factors predicts an extremely lower risk of CAD (12).

In a cohort study on 20000 men and women in Chicago with 22 years of follow-up, Lowe et al (13) found that when two or all three major risk factors (i.e., high cholesterol, high blood pressure, and cigarette smoking) were present, both men and women had a marked increase in the relative risk of coronary heart disease (5.5 and 5.7, respectively), cardiovascular disease (4.1 and 4.5), and allcause mortality (3.2 and 2.3).

Furthermore, the overall prevalence of CAD was low

Table 1. Prevalence of Coronary Risk Factors

\begin{tabular}{lcc}
\hline Risk Factor & Number & Percent \\
\hline Gender & & \\
Male & 656 & $73.3 \%$ \\
Female & 239 & $26.7 \%$ \\
Old age & & \\
$\quad$ Male $(\geq 45)$ & $615 / 656$ & $93.8 \%$ \\
Female $(\geq 55)$ & $163 / 239$ & $68.2 \%$ \\
Hypertension & 477 & $53.3 \%$ \\
Diabetes mellitus & 338 & $37.8 \%$ \\
Cigarette-smoking & 429 & $47.9 \%$ \\
Hyperlipidemia & 255 & $28.5 \%$ \\
Family history & 173 & $19.3 \%$ \\
Overweight and obesity & 547 & $61.1 \%$ \\
\hline
\end{tabular}




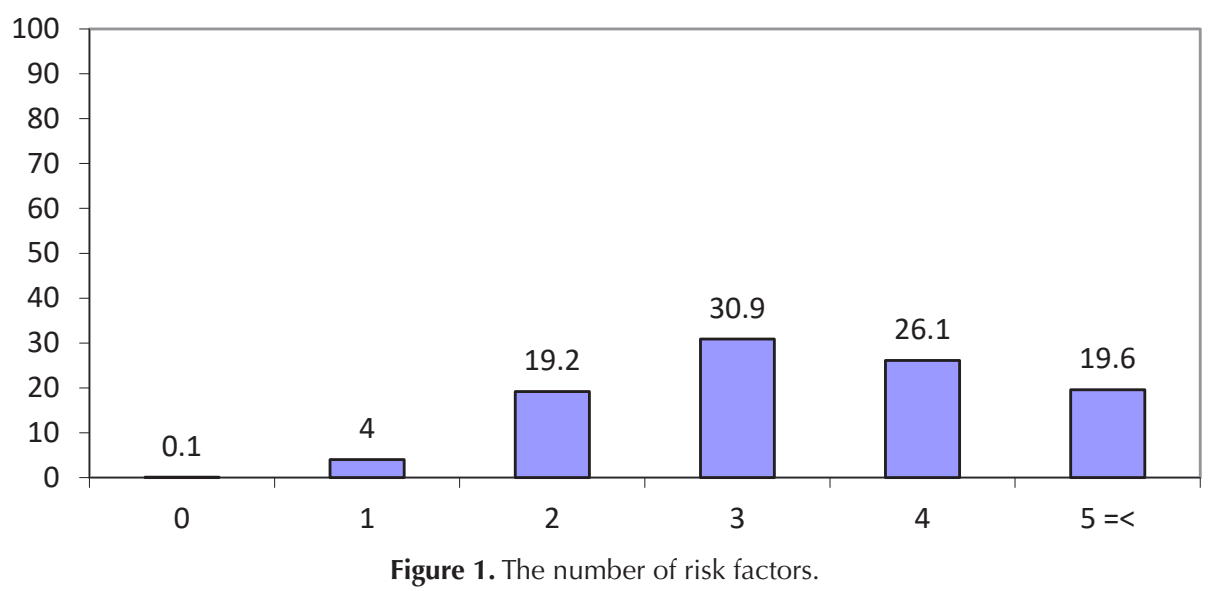

(1.8 and $1.1 \%$ in males and females) among 46239 Chinese adults within the age range of 20 or older during 2007-2008. Moreover, the prevalence of CAD risk factors was 36.7 and $29.8 \%$ (overweight or obese), 30.1 and $24.8 \%$ (hypertension), 64 and $67.4 \%$ (dyslipidemia), and 26.7 and $23.6 \%$ (hyperglycemia) in males and females, respectively (14).

In a study conducted in East Azerbaijan province of Iran, the incidence of coronary risk factors in the general population older than 30 years was $16.25 \%$ (hypertension), $7.45 \%$ (DM), $9.40 \%$ (smoking), and $47.64 \%$ (hypercholesterolemia). The prevalence of obesity (body mass index (BMI) $>30$ ) was $18.2 \%$ and $37.2 \%$ in men and women as well (15).

Based on the results of another study, the incidence of coronary risk factor in the general population in West Azerbaijan province was $17.38 \%$ (hypertension), $5.49 \% \quad(\mathrm{DM}), \quad 14.5 \% \quad$ (smoking), and $25.8 \%$ (hypercholesterolemia) and the prevalence of obesity
(BMI >25) was $48.8 \%$ (16).

CABG is one of the most common procedures performed during hospital stays and accounts for $1.4 \%$ of all operating room procedures (17). In Iran, there is no annual number regarding the documented published data about CABG patients, but it is approximately 25000 per year.

In our study, all risk factors in CABG patients were significantly higher compared to general people. In contrast to a Chinese study and similar to most studies, hypertension, DM, hypercholesterolemia, and obesity (BMI >30) were higher in women but smoking and positive family history were higher in men. This is probably due to low physical activity and low employment of Iranian women.

Additionally, Tate et al (18) found that the incidence of ischemic heart disease (IHD) increased from less than 1 per 1000 person-year in the age range of 35-39 years to over 18 per 1000 person-year within the age range of

Table 2. Prevalence of risk factors based on gender

\begin{tabular}{|c|c|c|c|c|}
\hline Risk Factor & Male & Female & Total & P Value \\
\hline Old age $(\geq 60)$ & $303(46.2 \%)$ & $135(56.5 \%)$ & $438(48.9 \%)$ & 0.006 \\
\hline Hypertension & 332 (50.6\%) & $145(60.7 \%)$ & 477 (53.3\%) & 0.005 \\
\hline Diabetes mellitus & $214(32.6 \%)$ & $124(51.9 \%)$ & $338(37.8 \%)$ & 0.001 \\
\hline Cigarette-smoking & 383 (58.4\%) & $46(19.2 \%)$ & 429 (47.9\%) & 0.001 \\
\hline Hyperlipidemia & $151(23 \%)$ & $104(43.5 \%)$ & $255(28.5 \%)$ & 0.001 \\
\hline Family history & $138(21 \%)$ & $35(14.6 \%)$ & $173(19.3 \%)$ & 0.01 \\
\hline Overweight and obesity & 384 (58.5\%) & $163(68.2 \%)$ & $547(61.1 \%)$ & 0.005 \\
\hline
\end{tabular}

Table 3. Prevalence of risk factors according to age

\begin{tabular}{|c|c|c|c|c|c|}
\hline Risk Factor & Age $<55$ & Age 55-70 & Age $>70$ & Total & $P$ Value \\
\hline Hypertension & $105 / 231(45.5 \%)$ & $303 / 525(57.7 \%)$ & 69/139 (49.6\%) & 477/895 (53.3\%) & 0.005 \\
\hline Diabetes mellitus & $97 / 231(42 \%)$ & $219 / 525(41.7 \%)$ & $22 / 139(15.8 \%)$ & $338 / 895(37.8 \%)$ & 0.001 \\
\hline Cigarette-smoking & $115 / 231(49.8 \%)$ & $254 / 525(48.4 \%)$ & $60 / 139(43.2 \%)$ & $429 / 895(47.9 \%)$ & 0.44 \\
\hline Hyperlipidemia & 78/231 (38.8 \%) & $144 / 525(27.4 \%)$ & $33 / 139(23.7 \%)$ & $255 / 895(28.5 \%)$ & 0.08 \\
\hline Family history & $81 / 231(35.1 \%)$ & $86 / 525(16.4 \%)$ & $6 / 139(4.3 \%)$ & 173/895 (19.3\%) & 0.001 \\
\hline Overweight and obesity & $174 / 231(75.3 \%)$ & $320 / 525(61 \%)$ & $53 / 139(38.1 \%)$ & $547 / 895(61.1 \%)$ & 0.001 \\
\hline
\end{tabular}


75-79 years. However, the adjusted relative risk of IHD for hypertension and smoking showed a significant decline $(P=0.001)$ with advancing age but that of the BMI and the presence of DM for ischemic heart disease failed to vary with age $(P=0.05)$. In addition, the mean age was 60.4 years (within the range of 40-93 years) and most patients undergoing $C A B G$ were in the age group of 55-70 years. The mean age in other similar studies was 57 to 62 years $(5,10,19,20)$. The frequency of patients older than 70 years in our study was $15.5 \%$, which was significantly high compared to that in a previous study $(10.6 \%)(5)$. Today, surgery can be conducted in older patients owing to the advances in medical science, increased life expectancy, and the improvement of cardiac surgery techniques. Based on the results, the prevalence of smoking failed to vary with age $(P=0.44)$ but that of obesity, DM, dyslipidemia, and positive family history reduced with advancing age $(P=0.08$ to 0.001$)$. The highest prevalence of hypertension as a risk factor was observed among the patients in 55-70-year-old group.

Male gender is one of CAD risk factors, while its potential mechanisms are unknown (21). Ostovan et al reported that all CAD risks were $32 \%$ (in women) and $49 \%$ (in men) during life for individuals at age 40 (22). Similar to all other studies (64-94\%), in our study, most of the patients were males $(73.3 \%)$ while in contrast to most studies, the mean age of male and female participants was not significantly different (10).

The prevalence of diabetes in the general population is approximately $8 \%(15,23)$ whereas it is found 27.6 to $54.1 \%$ in other similar studies, which is always more common in females $(5,20)$. Likewise, the incidence of DM among the general population was $37.8 \%$ (female: $51.9 \%$ ) in our study. We showed that the prevalence of diabetes in under 55 years old group was more than those of the other groups (older than 55-year group), and surprisingly, there was an inverse relationship between age and diabetes. The researcher believes that most patients have insufficient knowledge about the cause and control of their diabetes. For example, the misleading naming of diabetes in Iran (i.e., sugar disease instead of DM) is one of such issues. Further, denial, traditional treatments, and the fear of insulin therapy in many patients are considered as other challenges that impede proper diabetes treatment.

Based on the findings of Lawes et al, hypertension accounted for an estimated 54\% of all strokes and $47 \%$ of all ischemic heart disease events worldwide (24). Terada et al (11) also reported that after adjustment for the other factors, $28 \%$ of CAD events in men and $29 \%$ in women were attributable to blood pressure levels that exceeded the high normal rate (130/85). The prevalence of hypertension in the general population is approximately $8 \%(15,23)$. One study revealed a sharp increase in the prevalence of hypertension by age and greater risk in females (25). In our study, hypertension was more common in women, but there was no age-related increase in hypertension. The incidence of hypertension in other similar studies was $39.4-81.5 \%(5,20)$. Regular blood pressure measurements and proper treatment were not optimal in our patients and thus required increasing levels of education and information.

In another study, the risk percent associated with elevated total cholesterol $(200 \mathrm{mg} / \mathrm{dL})$ was $27 \%$ in men and $34 \%$ in women (7). The prevalence of dyslipidemia in the general population of West Azerbaijan province was approximately $25.8 \%$ that was relatively low compared to all provinces of Iran (16). Similarly, the occurrence of dyslipidemia in other similar studies was 49.2-85.6 \% (10, 19). In our study, dyslipidemia was supposed to be more common among females, while its prevalence was lower $(28.5 \%)$. In other words, there was an inverse relationship between age and dyslipidemia, and the prevalence of dyslipidemia was more common in the group under 55 years of age. In West Azerbaijan province and most rural areas, a special type of cooking oil called "animal oil or yellow oil" is used, which is an ultra-saturated and harmful oil. Determining the role of cooking oil in CADs requires further research.

The incidence of myocardial infarction increases six-fold in women and threefold in men who smoke at least 20 cigarettes per day compared to those who never smoke (26). The smoking prevalence in men is 6.02 times more than that in women in Iran. In another study, the prevalence of smoking was $19-24 \%$ and $0.8-4.7 \%$ in men and women, respectively (27). Based on the findings of a study performed in East Azerbaijan province (28), the incidence of smoking in patients with acute myocardial infarction significantly decreased (from $55.5 \%$ to $34 \%$ ) in the past two decades $(P<0.001)$. In contrast, in another study, the prevalence of smoking in West Azerbaijan $(14.5 \%)$ ranked the second after East Azerbaijan (first place with $14.8 \%$ ) among the general population of all provinces of Iran (16). In our study, cigarette smoking was more common in men and no age-related correlation was observed in this regard. The prevalence of cigarette smoking in other similar studies was 9.4-66.6\% (19). Increasing awareness as well as raising taxes and the cost of the cigarette is recommended as the ways to reduce cigarette smoking.

Obesity is more common in developed countries, for example, approximately 35\% of the United States population is obese (29). Furthermore, obesity increases all the atherogenic risk factors, while it reduces physical activity, and thus patients are exposed to CAD (30). There is a continuous linear relationship between higher BMI and greater risk of CAD (31). The prevalence of patients with obesity (or BMI more than 30) in our study was $26.1 \%$, which is significantly higher than that of the other studies (14.6-21.2\%) conducted by Ostovan et al (10) and Pieris et al (20). Based on the findings of the current study, 
the prevalence of obesity was more in under 55 years old group as compared to the other groups (older than 55 years group) and an inverse relationship was observed between age and obesity. Obesity is sometimes, especially in rural women patients considered as one of the health marks and thus, the lack of the acceptance of obesity outcomes by the patient is regarded as the main problem of these patients.

Similarly, family history is an independent risk factor for CAD, particularly among younger individuals with a family history of premature disease. The risk of developing $\mathrm{CAD}$ in the presence of a positive family history ranges from 15 to $100 \%$ in various cohorts, which mostly show a $40 \%-60 \%$ increase (32). Individuals from families with two or more premature cardiovascular deaths among the firstdegree relatives had a threefold greater risk of developing CAD before the age of 50 (33). Mandegar et al (5) and Pieris et al (20) reported a positive family history of $40.3 \%$ and $12.3 \%$. In our study, the percentage of family history was $19.3 \%$, which is close to the finding of Kasliwal et al (19). The reliability of a self-reported family history of CAD was explored in a study through which 1628 children completed a questionnaire regarding parental medical history. Regarding cardiac death, the positive predictive value was only $47 \%-66 \%$ while the predictive value of a negative statement was above $90 \%$ for the family history of cardiac death. Therefore, they suggested that although obtaining family history information is valuable, selfreported information might not be accurate (34). In our study, most of the patients with a positive family history were under 55-year-old men and the presence of positive family history reduced with advancing age.

In the United States, the prevalence of obesity increased dramatically (15\% to $30 \%)$ during $1960-2000$ and there was an increase in diagnosed diabetes (1.8\% to $5.0 \%)$ that was most prominent in obese subjects $(2.9 \%$ to $10.1 \%)$. In contrast, serum total cholesterol $\geq 240 \mathrm{mg} / \mathrm{dL}$ ( $34 \%$ to $17 \%)$, hypertension ( $31 \%$ to $15 \%)$, and smoking (39\% to $26 \%$ ) decreased substantially. These changes occurred in all weight groups and were associated with increases in the use of lipid-lowering drugs and antihypertensive medications (2). Conversely, however, the prevalence of most risk factors was more common in under 55-year group, especially in women in the current study, which is a warning for an increase in CAD in the future. In a similar study implemented in the northeast of Iran during 20082011, none of the risk factors demonstrated a decline, which corroborates with the findings of the present study. Obesity reached from $10.7 \%$ to $18.8 \%$ and dyslipidemia, especially low high-density lipoprotein showed an increase as well (35).

\section{Conclusion}

In our study, the most prevalent modifiable risk factors were hypertension, smoking, DM, dyslipidemia, and obesity, respectively. In addition, non-modifiable risk factors were male gender, old age, and positive family history.

The prevalence of DM, dyslipidemia, and obesity were more common in under 55-year group, especially in women. Accordingly, it is suggested to perform intervention programs in order to modify people's lifestyle. It is recommended that planning priorities focus on reducing smoking in all ages, especially in men, and physical activity and dieting increase to avoid overweight in women, along with the serious blood pressure be controlled in both genders.

\section{Conflict of interests}

None.

\section{Ethical considerations}

This study was approved by the Ethics Committee of Urmia University of Medical Sciences (ir.umsu.rec.1395.263).

\section{References}

1. Thom T, Haase N, Rosamond W, Howard VJ, Rumsfeld J, Manolio T, et al. Heart disease and stroke statistics--2006 update: a report from the American Heart Association Statistics Committee and Stroke Statistics Subcommittee. Circulation. 2006;113(6):e85-151. doi: 10.1161/ circulationaha.105.171600.

2. Gregg EW, Cheng YJ, Cadwell BL, Imperatore G, Williams $\mathrm{DE}$, Flegal KM, et al. Secular trends in cardiovascular disease risk factors according to body mass index in US adults. JAMA. 2005;293(15):1868-74. doi: 10.1001/jama.293.15.1868.

3. Sarrafzadegan N, Kelishadi R, Esmaillzadeh A, Mohammadifard N, Rabiei K, Roohafza H, et al. Do lifestyle interventions work in developing countries? Findings from the Isfahan Healthy Heart Program in the Islamic Republic of Iran. Bull World Health Organ. 2009;87(1):39-50. doi: 10.2471/ blt.07.049841.

4. Smith SC Jr, Benjamin EJ, Bonow RO, Braun LT, Creager MA, Franklin BA, et al. AHA/ACCF Secondary Prevention and Risk Reduction Therapy for Patients with Coronary and other Atherosclerotic Vascular Disease: 2011 update: a guideline from the American Heart Association and American College of Cardiology Foundation. Circulation. 2011;124(22):245873. doi: 10.1161/CIR.0b013e318235eb4d.

5. Mandegar M, Marzban M, Lebaschi A, Ghaboussi P, AlaiAlamooti A, Ardalan A. Cardiovascular risk factors and inhospital mortality in 1258 cases of coronary artery bypass surgery in Tehran heart center. Acta Med Iran. 2008;46(5):38690.

6. Gokhale K. Heart Surgery in India for $\$ 1,583$ Costs $\$ 106,385$ in U.S. Bloomberg. July 28, 2013. https://www.bloomberg. com/news/articles/2013-07-28/heart-surgery-in-india-for-1 583-costs-106-385-in-u-s-.

7. Yusuf S, Hawken S, Ounpuu S, Dans T, Avezum A, Lanas F, et al. Effect of potentially modifiable risk factors associated with myocardial infarction in 52 countries (the INTERHEART study): case-control study. Lancet. 2004;364(9438):937-52. doi: 10.1016/s0140-6736(04)17018-9.

8. Sanchis-Gomar F, Perez-Quilis C, Leischik R, Lucia A. Epidemiology of coronary heart disease and acute coronary syndrome. Ann Transl Med. 2016;4(13):256. doi: 10.21037/ atm.2016.06.33.

9. Ebrahimi M, Kazemi-Bajestani SM, Ghayour-Mobarhan M, Ferns GA. Coronary artery disease and its risk factors status in iran: a review. Iran Red Crescent Med J. 2011;13(9):610-23.

10. Ostovan MA, Darvish N, Askarian M. The prevalence of risk 
factors of coronary artery disease in the patients who underwent coronary artery bypass graft, Shiraz, Iran: suggesting a model. Int Cardiovasc Res J. 2014;8(4):139-42.

11. Terada T, Johnson JA, Norris C, Padwal R, Qiu W, Sharma AM, et al. Severe obesity is associated with increased risk of early complications and extended length of stay following coronary artery bypass grafting surgery. J Am Heart Assoc. 2016;5(6). doi: 10.1161/jaha.116.003282.

12. Stamler J, Stamler R, Neaton JD, Wentworth D, Daviglus $M L$, Garside D, et al. Low risk-factor profile and long-term cardiovascular and noncardiovascular mortality and life expectancy: findings for 5 large cohorts of young adult and middle-aged men and women. JAMA. 1999;282(21):2012-8. doi: 10.1001/jama.282.21.2012.

13. Lowe LP, Greenland P, Ruth KJ, Dyer AR, Stamler R, Stamler J. Impact of major cardiovascular disease risk factors, particularly in combination, on 22-year mortality in women and men. Arch Intern Med. 1998;158(18):2007-14.

14. Yang ZJ, Liu J, Ge JP, Chen L, Zhao ZG, Yang WY. Prevalence of cardiovascular disease risk factor in the Chinese population: the 2007-2008 China National Diabetes and Metabolic Disorders Study. Eur Heart J. 2012;33(2):213-20. doi: 10.1093/ eurheartj/ehr205.

15. Khalili A, Yaghoubi A, Safaie N, Eyvazi K, Azarfarin R, Ebrahimzadeh $\mathrm{A}$, et al. Incidence of Cardiovascular Risk Factors in Oskoo (Northwest Iran): An Approach through WHO CVD-risk Management Package for Low-and MediumResource Settings on 37,329 Adults $>/=30$ Years Old. J Cardiovasc Thorac Res. 2011;3(4):103-8. doi: 10.5681/ jcvtr.2011.023.

16. Ahmadi A, Mobasheri M, Soori H. Prevalence of major coronary heart disease risk factors in Iran. Int J Epidemiol Res. 2014;1(1):3-8

17. Weiss AJ, Elixhauser A, Andrews RM. Characteristics of Operating Room Procedures in U.S. Hospitals, 2011: Statistical Brief \#170. Healthcare Cost and Utilization Project (HCUP) Statistical Briefs. Rockville (MD): Agency for Healthcare Research and Quality (US); 2006.

18. Tate RB, Manfreda J, Cuddy TE. The effect of age on risk factors for ischemic heart disease: the Manitoba Follow-Up Study, 1948-1993. Ann Epidemiol. 1998;8(7):415-21.

19. Kasliwal RR, Kulshreshtha A, Agrawal S, Bansal M, Trehan N. Prevalence of cardiovascular risk factors in Indian patients undergoing coronary artery bypass surgery. J Assoc Physicians India. 2006;54:371-5.

20. Pieris RR, Al-Sabti HA, Al-Abri QS, Rizvi SG. Prevalence pattern of risk factors for coronary artery disease among patients presenting for coronary artery bypass grafting in Oman. Oman Med J. 2014;29(3):203-7. doi: 10.5001/ omj.2014.50.

21. Charchar FJ, Bloomer LD, Barnes TA, Cowley MJ, Nelson $\mathrm{CP}$, Wang $\mathrm{Y}$, et al. Inheritance of coronary artery disease in men: an analysis of the role of the $\mathrm{Y}$ chromosome. Lancet. 2012;379(9819):915-22. doi: 10.1016/s0140-6736(11)614530.

22. Lloyd-Jones DM, Larson MG, Beiser A, Levy D. Lifetime risk of developing coronary heart disease. Lancet. 1999;353(9147):89-92. doi: 10.1016/s0140-6736(98)10279-
9.

23. Esteghamati A, Meysamie A, Khalilzadeh O, Rashidi A, Haghazali M, Asgari F, et al. Third national Surveillance of Risk Factors of Non-Communicable Diseases (SuRFNCD-2007) in Iran: methods and results on prevalence of diabetes, hypertension, obesity, central obesity, and dyslipidemia. BMC Public Health. 2009;9:167. doi: 10.1186/1471-2458-9-167.

24. Lawes CM, Vander Hoorn S, Rodgers A. Global burden of bloodpressure-related disease, 2001. Lancet. 2008;371(9623):15138.doi:10.1016/s0140-6736(08)60655-8.

25. Haghdoost AA, Sadeghirad B, Rezazadehkermani M. Epidemiology and heterogeneity of hypertension in Iran: a systematic review. Arch Iran Med. 2008;11(4):444-52. doi: 08114/aim.0017.

26. Prescott E, Hippe M, Schnohr P, Hein HO, Vestbo J. Smoking and risk of myocardial infarction in women and men: longitudinal population study. BMJ. 1998;316(7137):1043-7. doi: $\quad 10.1136 / \mathrm{bmj} .316 .7137 .1043$.

27. Moosazadeh M, Ziaaddini H, Mirzazadeh A, AshrafiAsgarabad A, Haghdoost AA. Meta-analysis of Smoking Prevalence in Iran. Addict Health. 2013;5(3-4):140-53.

28. Ghaffari S, Hakim H, Pourafkari L, Sagheb AsI E, Goldust M. Twenty-year route of prevalence of risk factors, treatment patterns, complications, and mortality rate of acute myocardial infarction in Iran. Ther Adv Cardiovasc Dis. 2013;7(3):117-22. doi: $10.1177 / 1753944712474093$.

29. Ogden CL, Carroll MD, Kit BK, Flegal KM. Prevalence of childhood and adult obesity in the United States, 2011-2012. JAMA. 2014;311(8):806-14. doi: 10.1001/jama.2014.732.

30. Dannenberg AL, Keller JB, Wilson PW, Castelli WP. Leisure time physical activity in the Framingham Offspring Study. Description, seasonal variation, and risk factor correlates. Am J Epidemiol. 1989;129(1):76-88. doi: 10.1093/oxfordjournals. aje.a115126.

31. Jensen MD, Ryan DH, Apovian CM, Ard JD, Comuzzie AG, Donato KA, et al. 2013 AHA/ACC/TOS guideline for the management of overweight and obesity in adults: a report of the American College of Cardiology/American Heart Association Task Force on Practice Guidelines and The Obesity Society. Circulation. 2014;129(25 Suppl 2):S102-38. doi: 10.1161/01. cir.0000437739.71477.ee.

32. Sesso HD, Lee IM, Gaziano JM, Rexrode KM, Glynn RJ, Buring JE. Maternal and paternal history of myocardial infarction and risk of cardiovascular disease in men and women. Circulation. 2001;104(4):393-8. doi: 10.1161/hc2901.093115.

33. Ranthe MF, Carstensen L, Oyen N, Tfelt-Hansen J, Christiansen M, McKenna WJ, et al. Family history of premature death and risk of early onset cardiovascular disease. J Am Coll Cardiol. 2012;60(9):814-21. doi: 10.1016/j.jacc.2012.06.018.

34. Murabito JM, Nam BH, D'Agostino RB, Sr., Lloyd-Jones DM, O'Donnell CJ, Wilson PW. Accuracy of offspring reports of parental cardiovascular disease history: the Framingham Offspring Study. Ann Intern Med. 2004;140(6):434-40. doi: 10.7326/0003-4819-140-6-200403160-00010.

35. Siadat M, Kazemi T, Hajihosseni M. Cardiovascular RiskFactors in the Eastern Iranian Population: Are We Approaching 25x25 Target? J Res Health Sci. 2016;16(1):51-2. 